\title{
LOW COST MEMBRANE CONTACTORS BASED ON HOLLOW FIBRES
}

\begin{abstract}
Mirko DOHNAL, Tomas VESELY, Miroslav RAUDENSKY`
Abstract: Membrane contactors are used to solve different chemical engineering tasks (e.g. water saturation with gases). Such elements are traditionally used for bubble less oxidation of blood. However, their industrial applications are rather limited by their high investment costs. This is probably the main reason why membrane contactors are not used so widely, e.g. classical absorbers, etc. If potted bundles of hollow fibres are available, then it is a relatively simple task to design an ad hoc membrane contactor. However, it must be emphasised that to achieve the highest mass transfer efficiency requires a rather time-consuming tuning of each ad hoc designed contactor. To check the differences by water evaporation were aligned two modes, the water inside the hollow fibre membrane and fan air outside, next with the water outsides and flowing pressure air inside the membrane.
\end{abstract}

\section{INTRODUCTION}

A membrane contactor is a device that achieves gas/liquid or liquid/liquid mass transfer without dispersion of one phase within another, see e.g. [1]. This is accomplished by passing the fluids on opposite sides of a micro porous membrane. By careful control of the pressure difference between the fluids, one of the fluids is immobilized in the pores of the membrane so that the fluid/fluid interface is located at the mouth of each pore.

Membrane contactors typically offer 20 - 30 times more surface area per cubic meter than what is achievable in gas absorbers and 300 - 500 times what is obtainable in liquid/liquid extraction columns, leading to remarkably low HTU values. Flood resistances absence of emulsions, no flooding at high flow rates, no unloading at low flow rates, no density difference between fluids etc., are additional chemical engineering advantages.

Membrane contactors have been used to solve a broad spectrum of different chemical engineering tasks as e.g. remove gases from liquids or add gas to liquids. However, price sensitive tasks as e.g. elimination of ammoniac from waste water or from air cannot be covered by the membrane contactors currently available on the market as they are prohibitively expensive. Laboratory size and partially different pilot tests are described in many different papers, namely liquid/liquid and gas/liquid applications in fermentation, pharmaceuticals, wastewater treatment, chiral separations, semiconductor

\footnotetext{
-Mirko Dohnal, dohnal@fbm.vutbr.cz, Knowledge Engineering Centre, Faculty of Business and Management, Brno University of Technology, CZ, Tomas Vesely, vesely.t@fme.vutbr.cz,Miroslav Raudensky, raudensky@fme.vutbr.cz, Heat Transfer and Fluid Flow Laboratory, Faculty of Mechanical Engineering, Brno University of Technology, Technicka 2896/2;616 69, Brno; CZ
}

This is an Open Access article distributed under the terms of the Creative Commons Attribution License 2.0, which permits unrestricted use, distribution, and reproduction in any medium, provided the original work is properly cited. 
manufacturing, carbonation of beverages, metal ion extraction, protein extraction, VOC removal from waste gas, and osmotic distillation.On the other hand there are unsolved problems how to keep hydrophobicity of large scale contactors, cleaning of membrane surface etc.

Well known contactors Liqui-Cel ${ }^{\circledR}$ dominate the market for over 20 years. This type of contactors was originally developed for medical applications. However, e.g. blood oxidation requires totally bubble-less operation to eliminate e.g. brain / heart problems/risks.

Industrial contactors do not operate under such strict requirements. Therefore simple contactors with partial generation of bubbles are acceptable and because of their lower cost preferred. Moreover, the membrane contactors have displaced, under certain conditions, older technology such as vacuum towers, forced draft deaerators and oxygen scavengers. Unfortunately, there are still many problems with large scale contactors, see e.g. $[1,2]$. Brno University of Technology has several years of experience in different types of membrane contactor applications, see e.g. [3].

Although a number of membrane module geometries are possible, hollow fibre modules have received the most attention, see e.g. [4]. In general, tube side mass transfer coefficients can be predicted with reasonable accuracy; on the other hand, shell side coefficients are more difficult to determine, and several research groups are currently addressing this problem.

\section{Air Humidification}

Air humidification is a typical example of a price sensitive task. The application of membrane contactors in air humidity control offers advantages over the conventional treatment methods, e.g. dew pointing by cooling (high energy consumption) and direct absorption (risk of air contamination by the absorbent). In gas/liquid membrane contactors the applied absorption liquid is separated from the feed air by a liquid tight but water vapour permeable membrane. Air and absorption liquid can be operated independently of each other and large and well-defined contact areas are provided.

Traditionally, hollow fibre membrane contactors used for gas-liquid contacting are usually designed in a shell and tube configuration with shell-side fluid flowing parallel to the fibre-side fluid, either in co-current or counter-current pattern. The primary limitations of these so-called 'parallel flow' contactors are the shell-side flow channelling or mal-distribution due to non-uniform packing of the hollow fibres, higher shell-side pressure drop and relatively lower mass transfer coefficients. These limitations can be eliminated or reduced substantially by placing hollow fibres perpendicular to the flow direction. In these cross-flow membrane contactors the concentrations of both fluids vary in both directions i.e. in the direction of the flow as well as in the direction perpendicular to the flow.

Evaporative cooling is a cost effective, efficient method of cooling air compared to conventional air-conditioning. There exist various methods of evaporative cooling, including direct evaporative cooling (DEC) and indirect evaporative cooling (IEC), both of which rely on recirculating water through a wetting media by spraying or allowing water to trickle through the media. DEC configurations allow water to come into direct contact with the air to be cooled, while IEC configurations utilize a heat exchanger with cooled air 
from a DEC unit. There are a variety of advantages to evaporative cooling technologies, most notably increased efficiency compared to conventional air-conditioning. Disadvantages of evaporative cooling, compared to conventional air conditioning, include water consumption and the potential for microbial growth due to a supply of stagnant water that is in contact with outside air [5]. These conditions aid in the spread of liquid phase-born bacterial diseases, such as Legionnaire's Disease. Prevention requires a careful maintenance routine which requires the addition of anti-bacterial agents to the feed water.

To address the disadvantages of conventional evaporative cooling technologies, research proposes the use of hydrophobic hollow fibre membranes as the wetting media in evaporative coolers [6]. The hollow fibre membranes provide several advantages over traditional evaporative cooling technologies. With hollow fibre membranes, water vapour interacts with air in membrane pores; these pores allow water vapour transfer but are too small $(0.1 \mu \mathrm{m})$ to allow microbial penetration, creating a sanitary wetting media that does not require the addition of anti-microbial agents. In addition, the hollow fibre membranes decrease water consumption, provide a large surface area to volume ratio that improves heat and mass transfer, eliminate liquid phase droplets in the air stream, decrease friction losses through the wetting media, eliminate water recirculation pumps, and potentially absorb pollutants into the liquid phase [7].

Membranes are already used in many separation processes such as filtration, electrodialysis, distillation, and a variety of membrane contactor technologies; membrane dehumidification and humidification are such technologies that address climate control.

Numerous studies have been carried out to address the use of membranes in indoor climate control. Johnson et al. [6] investigated mass and heat transfer of hydrophobic hollow fibre membranes used as the wetting media in evaporative cooling. They found that hollow fibre membranes were a potentially feasible alternative to traditional wetting media. In another evaporative cooling application, El-Dessouky et al. [8] proposed and investigated the use of membranes to reduce the humidity of intake air prior to exposure to an indirect evaporative cooling unit and a direct evaporative cooling unit in series to improve the overall evaporative cooling efficiency.

Fouling in membrane evaporative cooling can occur as mineral water-side fouling, nonmineral air-side fouling, or biological fouling.

Water-side mineral fouling occurs when minerals precipitate out of the feed solution and accumulate on the interior membrane surface. Srisurichan et al. [9] reported that particles were deposited on the wall of the membrane and not within the pores during membrane distillation, leading to scale formation. Scale formation increases the risk of membrane pore wetting, which may eventually lead to scale formation within the membrane pores [10] further decreasing water vapour flux. Calcium sulphate (CaSO4) and calcium carbonate ( $\mathrm{CaCO} 3$ ) are both minerals of concern due to their being found in most domestic potable waters. For these minerals to precipitate within the membrane lumen the solution must be supersaturated. Also, nucleation sites must be available for crystal growth to begin. Membrane pore openings (not within the pores), imperfections in the membrane structure, or foreign matter may act as nucleation sites for crystal growth. Calcium sulphate can precipitate as several species, but gypsum ( $\mathrm{CaSO} 4 \cdot 2 \mathrm{H} 2 \mathrm{O}$ ) is the dominant precipitate when temperatures are less than $98^{\circ} \mathrm{C}$ [11]. As these minerals precipitate from the feed solution, membrane pore openings become blocked or covered, decreasing the pore area for water vapour flow. 
Air side fouling occurs due to particulates being deposited on the membrane surface. Little information is available in the literature regarding air particulate membrane fouling during air cross flow. It is likely that particulate matter is deposited on the membrane surface, blocking the membrane pores, reducing the effective porosity and vapour transport. Additionally, particulate matter may be hydrophilic and will become wetted as water vapour is absorbed, leading to further reductions in water vapour flow and increasing the potential for pore wetting.

Biological fouling is a common problem with traditional evaporative cooling systems [12] and in membrane treatment technologies, but little attention has been paid to biological fouling on membranes exposed to the air. Although bacteria are not able to penetrate the membrane pores, in membrane evaporative cooling the outside membrane surface provides a moist, generally warm environment ideal for biological growth to occur. Introduction of biological organisms to the outside membrane surface occurs through the air stream contacting the membrane. Also, biological organisms can be introduced to the lumen of the fibre from contaminated feed water.

Mechanical de fouling (whipping) can be done by air, as described for heat exchanger [13]. De fouling process will be most intensive when air/water flow will be reversed to flood out the scale or other impurities from the pores of membrane. For this case should be the alignment with water outside of hollow fibre membrane the most effective conception.

\section{EXPERIMENTAL}

The bundle of 600 pcs polypropylene hydrophobic hollow fibres OD/ID 0.49/0.36 mm [Fig.1] was used with a dimension of slot pores $0,2 \times 0,7$ microns [Fig.3]. By the fibre length of $0.69 \mathrm{~m}$ the tested surface was $0.65 \mathrm{~m} 2$. The bundle was potted in PVC terminal tubes [Fig.2] and connected with common fittings parts.

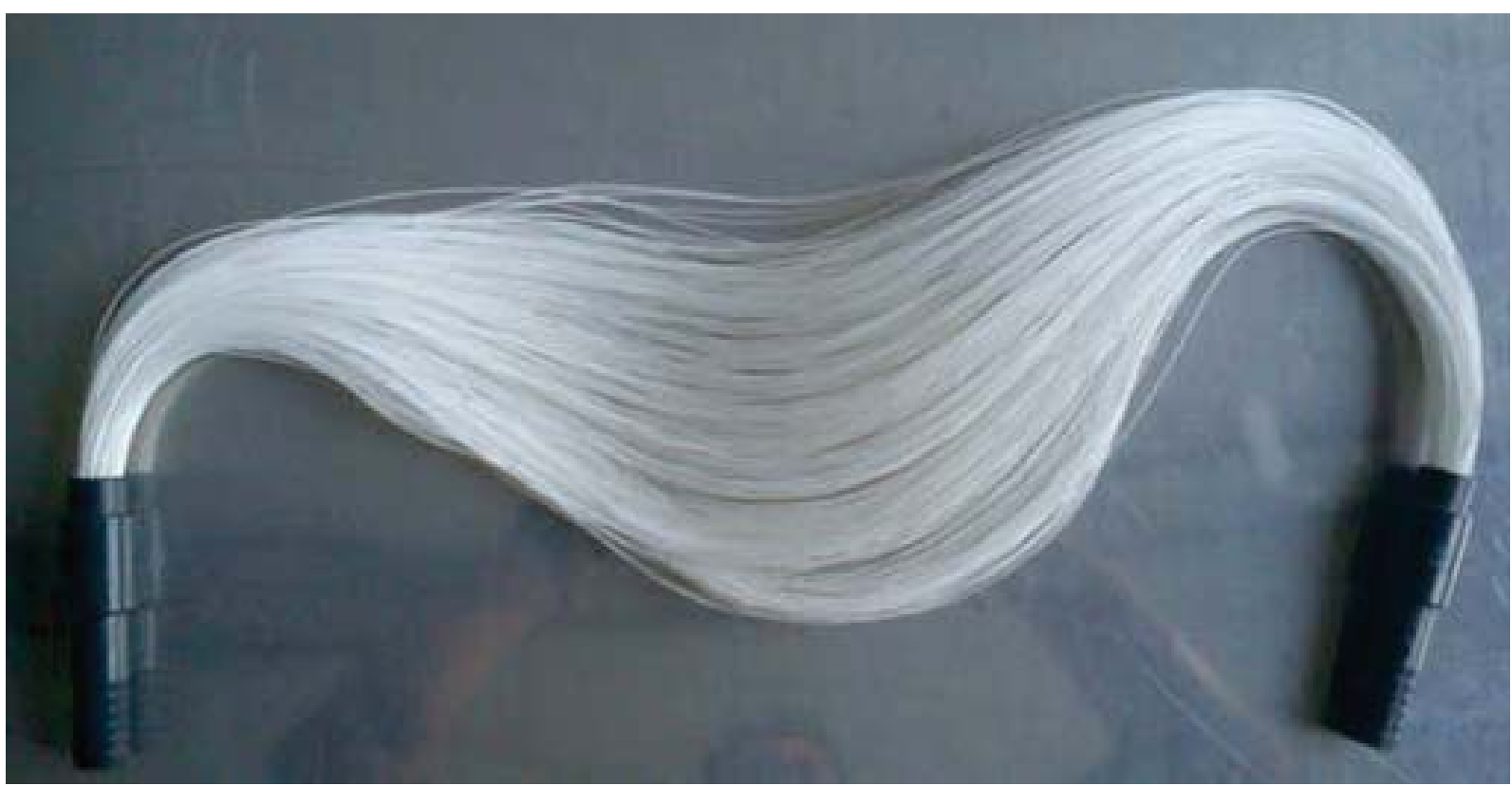

Figure 1: Bundle of hollow fibres with PVC terminals 


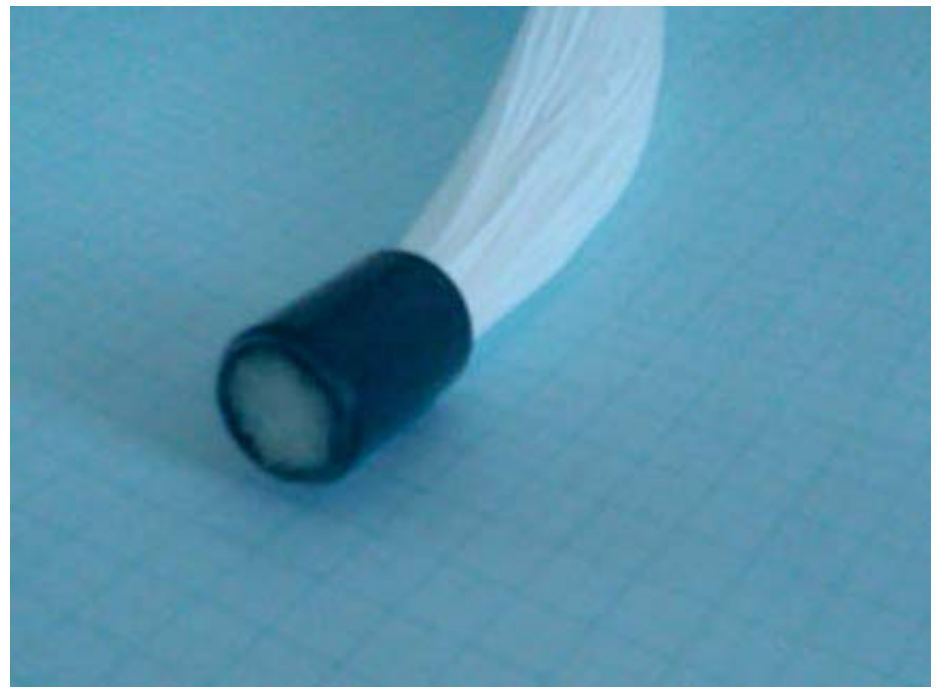

Figure 2: Potting of bundle in PVC tube

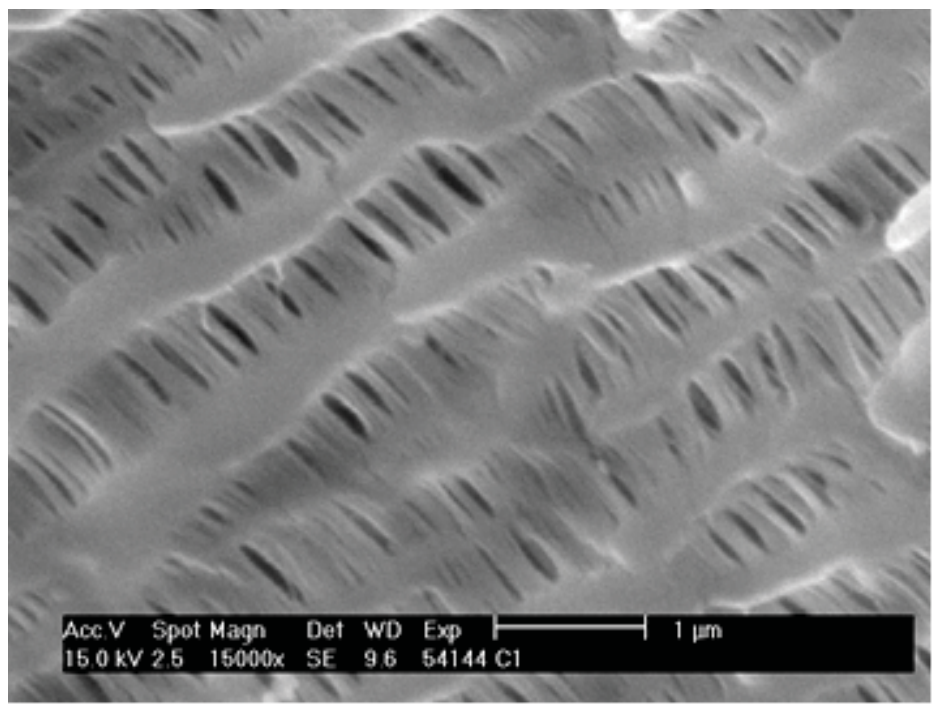

Figure 3: Electron microscopy picture of hollow fibre membrane

The first experimental apparatus was assembled as described in Fig.4, where the bundle of hollow fibres was laid out uniformly in fan stream in a diameter of $0.44 \mathrm{~m}$ and so the full surface $0.65 \mathrm{~m} 2$ was applied. Both temperatures (inlet, outlet) and the air flow velocity were measured. The water loss was first determined for free evaporating and subsequently by changed conditions of air flow and pressure of water inside hollow fibre membrane. 


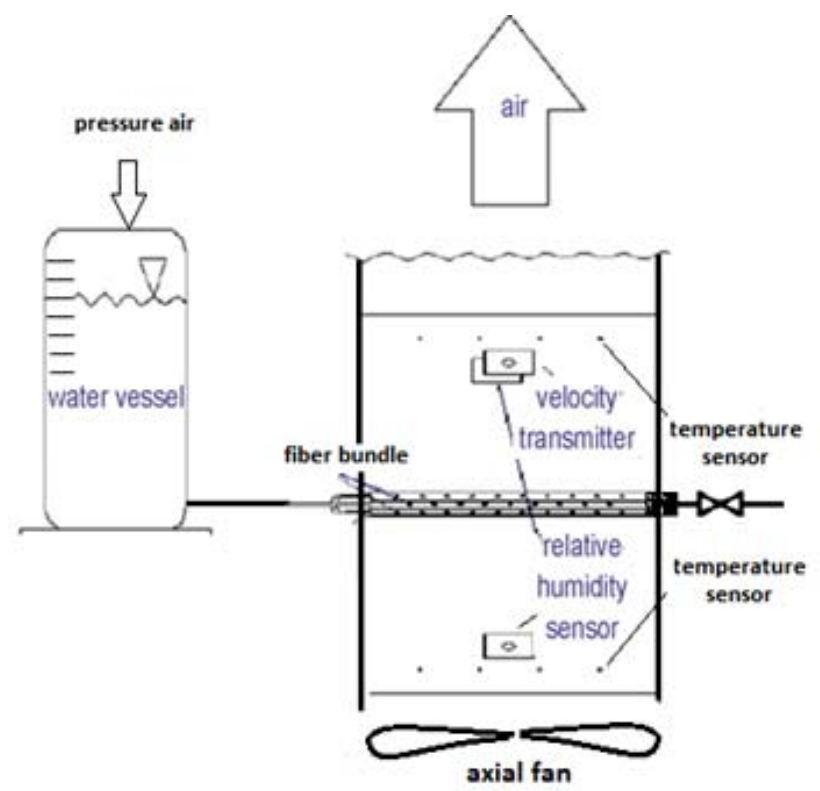

Figure 4: Layout for water inside of hollow fibres membrane and air flow outside

The items in Tab.1 describe the relations by evaporating of water through membrane bundle by changing conditions. General small changes of humidity and temperature were gauged by this mode.

Table 1: Values by mode according Fig.4 for different water pressure and air flow

\begin{tabular}{|c|c|c|c|c|c|c|c|c|}
\hline \multicolumn{2}{|r|}{ Water } & \multicolumn{3}{|c|}{ Air flow } & \multicolumn{2}{|c|}{ Relative humidity } & \multicolumn{2}{|c|}{ Air temperature } \\
\hline $\begin{array}{l}\mathrm{p}_{\mathrm{w}} \\
\text { [bar] }\end{array}$ & $\begin{array}{l}\text { permeance } \\
{[\mathrm{g} / \mathrm{h}]}\end{array}$ & $\begin{array}{l}\text { velocity } \\
{[\mathrm{m} / \mathrm{s}]}\end{array}$ & $\begin{array}{l}\text { volume } \\
{[\mathrm{m} 3 / \mathrm{h}]}\end{array}$ & $\begin{array}{l}\text { mass } \\
{[\mathrm{kg} / \mathrm{h}]}\end{array}$ & $\begin{array}{l}\mathrm{RH}_{\mathrm{i}} \\
{[\%]}\end{array}$ & $\begin{array}{l}\mathrm{RH}_{\circ} \\
{[\%]}\end{array}$ & $\begin{array}{l}\mathrm{t}_{\mathrm{i}} \\
{\left[{ }^{\circ} \mathrm{C}\right]}\end{array}$ & $\begin{array}{l}\mathrm{t}_{\mathrm{o}} \\
{\left[{ }^{\circ} \mathrm{C}\right]}\end{array}$ \\
\hline 1 & 14 & 0 & 0 & 0,0 & 50 & 50 & 24 & 24 \\
\hline 1 & 130 & 1,85 & 399,6 & 449,6 & 50 & 53 & 24 & 23,6 \\
\hline 1 & 150 & 2,6 & 561,6 & 631,8 & 52 & 57 & 24 & 23,2 \\
\hline 1 & 160 & 3,3 & 712,8 & 801,9 & 51 & 55 & 24 & 23,1 \\
\hline 2 & 130 & 2,6 & 561,6 & 631,8 & 53 & 57 & 24 & 23,2 \\
\hline 2 & 140 & 3,3 & 712,8 & 801,9 & 55 & 59 & 24 & 23 \\
\hline
\end{tabular}

The water content of entered and leaving air is determined via specific humidity by

$$
x=0,622 \frac{p_{v}}{p-p_{v}}=0,622 \frac{\varphi \cdot p_{v}{ }^{\prime \prime}}{p-\varphi \cdot p_{v}{ }^{\prime \prime}}
$$


and the difference of specific humidity compared with water loss corresponding per air mass.

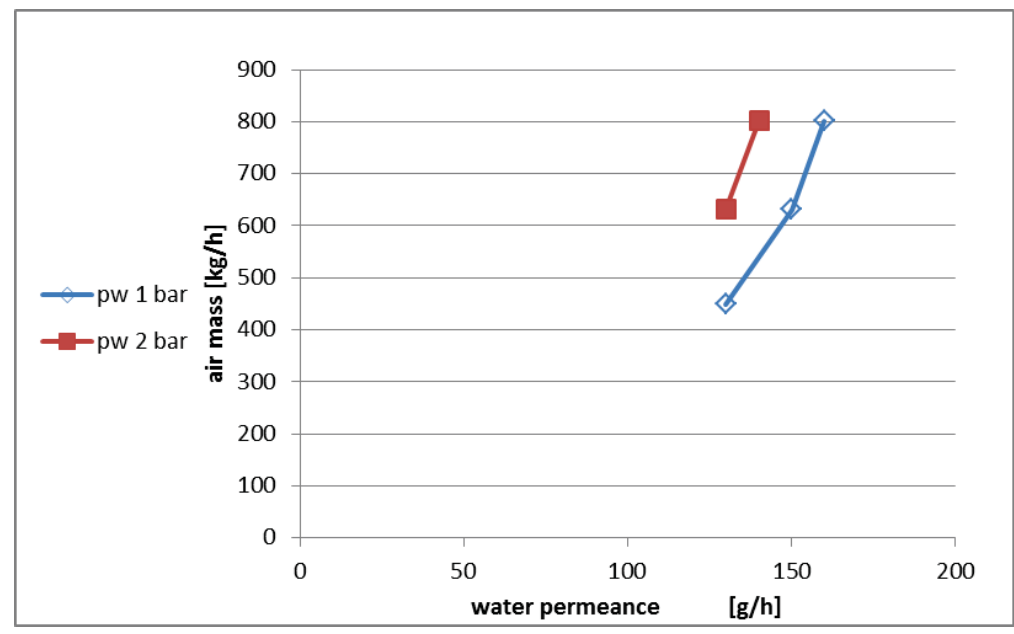

Figure 5: Plot of water loss by changing air mass flow and inside water pressure

Table 2: Differences in SH by RH and water loss calculation

\begin{tabular}{|r|lr|l|r|}
\hline \multicolumn{5}{|c|}{ Specific humidity } \\
\hline $\begin{array}{r}\mathrm{SH}_{\mathrm{i}} \\
{[\mathrm{g} / \mathrm{kg}]}\end{array}$ & $\begin{array}{l}\mathrm{SH}_{\mathrm{o}} \\
{[\mathrm{g} / \mathrm{kg}]}\end{array}$ & $\begin{array}{l}\Delta \mathrm{SH} \\
{[\mathrm{g} / \mathrm{kg}]}\end{array}$ & $\begin{array}{l}\Delta \mathrm{SH} \text { calc. from } \\
\text { water loss }[\mathrm{g} / \mathrm{kg}]\end{array}$ \\
\hline 9,60 & 9,59 & 0,00 & 0,00 \\
\hline 9,60 & 9,93 & 0,34 & 0,29 \\
\hline 9,98 & 10,43 & 0,45 & 0,24 \\
\hline 9,79 & 10,00 & 0,21 & 0,20 \\
\hline 10,18 & 10,43 & 0,25 & 0,21 \\
\hline 10,57 & 10,68 & 0,11 & 0,17 \\
\hline
\end{tabular}

The second experimental apparatus was set with idea to fulfil the condition to arrange the water outside the membrane wall. For this case the bundle of hollow fibres was built in a shell where water was supplied using pressure air. The dry pressure air was flown through hollow fibres. The assembling is illustrative in Fig. 5. 


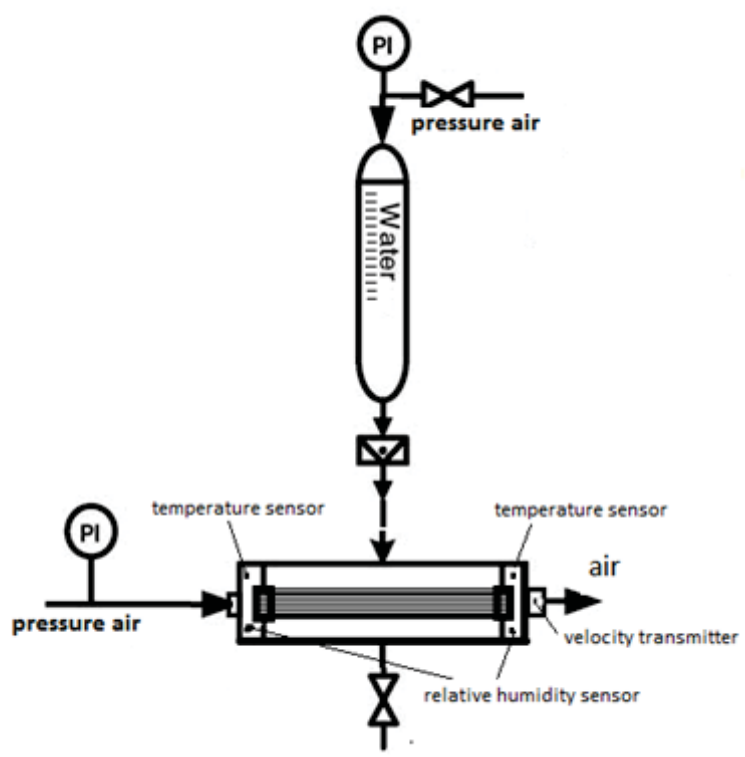

Figure 6: Layout for water outside and air flow inside of hollow fibres membrane

The dates are collected in Tab. 3 and describe the relations by evaporating of water through membrane bundle by various conditions.

Table 3: Collected dates from the measurement according to Fig. 6

\begin{tabular}{|c|c|c|c|c|c|c|c|c|c|}
\hline \multicolumn{2}{|c|}{ Water } & \multicolumn{4}{|c|}{ Air flow } & \multicolumn{2}{|c|}{$\begin{array}{l}\text { Relative } \\
\text { humidity }\end{array}$} & \multicolumn{2}{|c|}{$\begin{array}{c}\text { Air } \\
\text { temperature }\end{array}$} \\
\hline $\begin{array}{l}\mathrm{p}_{\mathrm{w}} \\
{[\mathrm{bar}]}\end{array}$ & $\begin{array}{l}\text { loss } \\
{[\mathrm{g} / \mathrm{h}]}\end{array}$ & $\begin{array}{l}\text { Inlet pressure } \\
\text { [bar] }\end{array}$ & $\begin{array}{l}\text { velocity } \\
{[\mathrm{m} / \mathrm{s}]}\end{array}$ & $\begin{array}{l}\text { volume } \\
{\left[\mathrm{m}^{3} / \mathrm{h}\right]}\end{array}$ & $\begin{array}{l}\text { mass } \\
{[\mathrm{kg} / \mathrm{h}]}\end{array}$ & $\begin{array}{l}\mathrm{RH}_{\mathrm{i}} \\
{[\%]}\end{array}$ & $\begin{array}{l}\mathrm{RH}_{\circ} \\
{[\%]}\end{array}$ & $\begin{array}{l}\mathrm{t}_{\mathrm{i}} \\
{\left[{ }^{\circ} \mathrm{C}\right]}\end{array}$ & $\begin{array}{l}\mathrm{t}_{\mathrm{o}} \\
{\left[{ }^{\circ} \mathrm{C}\right]}\end{array}$ \\
\hline 1 & 90 & 0,5 & 4 & 4,52 & 5,20 & 15 & 72 & 25 & 22,2 \\
\hline 1,5 & 100 & 1,0 & 6 & 6,78 & 7,80 & 25 & 82 & 24,2 & 21,3 \\
\hline 2 & 140 & 0,5 & 4 & 4,52 & 5,20 & 15 & 78 & 24,3 & 22,1 \\
\hline 2 & 160 & 1,5 & 8 & 9,04 & 10,40 & 25 & 75 & 24,6 & 20,3 \\
\hline 2 & 130 & 1,0 & 8 & 9,04 & 10,40 & 15 & 78 & 24,2 & 19,7 \\
\hline
\end{tabular}




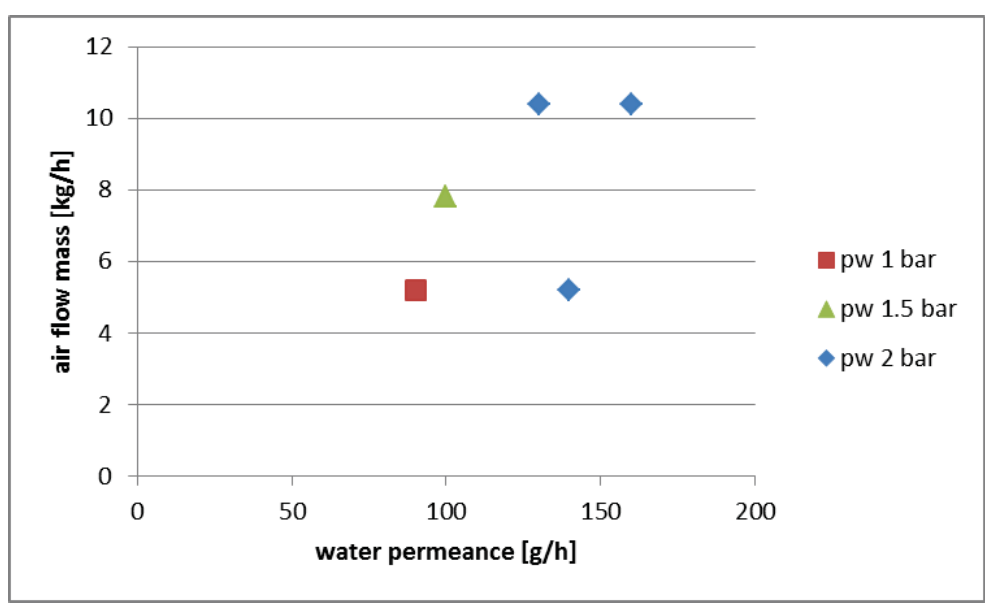

Figure 7: Plot of water loss by changing air mass flow and outside water pressure

The other dates were calculated by (2) to compare the values of specific humidity increase and water loss per air flowmass.

Table4: Calculated values of specific humidity

\begin{tabular}{|r|r|r|r|}
\hline \multicolumn{4}{|c|}{ Specific humidity } \\
\hline & & & $\Delta$ SH from \\
$\mathrm{SH}_{\mathrm{i}}$ & $\mathrm{SH}_{\circ}$ & $\Delta \quad \mathrm{SH}$ & $\begin{array}{l}\text { water loss } \\
{[\mathrm{g} / \mathrm{kg}]}\end{array}$ \\
\hline $3 \mathrm{~g} / \mathrm{kg}]$ & {$[\mathrm{g} / \mathrm{kg}]$} & {$[\mathrm{g} / \mathrm{kg}]$} \\
\hline 3,02 & 12,44 & 9,42 & 17,31 \\
\hline 4,82 & 13,44 & 8,62 & 12,82 \\
\hline 2,90 & 12,07 & 9,17 & 26,92 \\
\hline 4,91 & 10,95 & 6,05 & 15,39 \\
\hline 2,71 & 11,55 & 8,84 & 12,50 \\
\hline
\end{tabular}

As shown in Tab.4, the specific humidity increase which is related from a relative humidity measuring is less significant as that one from water loss. That should be caused by a leakage of a water droplet through the membrane wall. For these cases should be installed a water separator in the line of air flow.

\section{CONCLUSION}

The water vapour permeability and related humidity increase in relation to transferred air mass is evidently more effective by the alignment with air flow inside the hollow fibre membrane. The efficiency of evaporative cooling was also checked by this alignment. On the contrary the pressure drop is relative big in the case of $0.7 \mathrm{~m}$ long fibre membrane. A suitable solution is to prepare the contactors with shorter fibres. For reasons of inner contamination of an apparatus the fouling problems occur although the distilled water was used by trials. By these cases helps the bubbling of inner air through the membrane wall by decrease of water pressure and permeability function is fully renewed. As mentioned the scale fouling by using of tap water should be the same problem and furthermore the polluted water from de-fouling process can be took away by simply bypass. 


\section{ACKNOWLEDGEMENT}

The paper presented has been supported by European Regional Development Fund in the framework of the research project NETME Centre under the Operational Programme Research and Development for Innovation, CZ. 1.05/2.1.00/01.0002, ED0002/01/01.

\section{REFERENCES}

[1] Lazarova G. Z., SyskaB.,SchügerK.: Application of large-scale hollow fiber membrane contactors for simultaneous extractive removal and stripping of penicillin, Journal of Membrane Science Vol. 202, Issues 1-2, 15 June 2002, 151-164

[2] Gabelman A., Hwang S.-T.: Hollow fiber membrane contactors, Journal of Membrane Science, Volume 159, Issues 1-2, 1 July 1999, 61-106

[3] Malý J., Malá J., Tvarůžek P., Odstranováníamoniaku z kalové vody membránovou technologií, 4. Mezinárodní konference ODPADNI VODY 2001, Mladá Boleslav

[4] Kneifel K., NowakS., AlbrechtW., HilkeR., JustR., PeinemannK.-V.: Hollow fiber membrane contactor for air humidity control: Modules and membranes, Journal of Membrane Science, Volume 276, Issues 1-2, 1 May 2006, 241-251

[5] SellersD.A.: Evaporative cooling: design considerations, HPAC heating, piping, Air Condition. Eng. 76 (2004) 10-19.

[6] Johnson D.W., YavuzturkC., Pruis].: Analysis of heat and mass transfer phenomena in hollow fibre membranes used for evaporative cooling, J. Membr. Sci. 227 (2003) 159-171.

[7] Chiari A.: Air humidification with membrane contactors: experimental and theoretical results, Int. J. Ambient Ener. 21 (2001) 187-195

[8] El-Dessouky H.T., EttouneyH.M., BouhamraW.: A novel air conditioning system:membrane air drying and evaporative cooling, Chem. Eng. R. D. 78 (2000)999-1009.

[9] Srisurichan S., JiraratananonR., FaneA.G.: Mass transfer mechanisms and transport resistances in direct contact membrane distillation process, J. Membr. Sci. 277 (2006) 186-194.

[10] Gryta M.: Influence of polypropylene membrane surface porosity on the performance of membrane distillation process, J. Membr. Sci. 287 (2007) 6778.

[11] Chong T.H., SheikholeslamiR.: Thermodynamics and kinetics for mixed calcium carbonate and calcium sulfate precipitation, Chem. Eng. Sci. 56 (2001) 53915400.

[12] Buecker B., PostR.: Control biofouling in evaporative cooling systems, Chem. Eng. Progress 94 (1998) 45-50.

[13] Dohnal M., Pollmann K., Kutschke S., GuentherT., HorskyJ., RaudenskyM.: Feasible de fouling methods of flexible plastic heat exchanger, 2011, Heat exchanger fouling and cleaning, Crete, Greece 